\title{
ANATOMIA COMPARADA DO LENHO DE RAIZ E CAULE DE Aegiphila sellowiana Cham. (VERBENACEAE)
}

\author{
Selma Lopes Goulart ${ }^{1}$
}

(recebido: 27 de novembro de 2010; aceito: 29 de junho de 2012)

\begin{abstract}
RESUMO: O trabalho vem contribuir com informações sobre a anatomia estrutural da madeira de raiz e caule de Aegiphila sellowiana Cham. (Verbenaceae). O estudo foi conduzido em área de cerrado, no município de Pratânia, estado de São Paulo. Três espécimes de A. sellowiana foram coletados. Amostras do caule foram coletadas à altura do peito (AP), a 1,30 m do solo, amostras de raízes foram coletadas de 30 a $40 \mathrm{~cm}$ da base do tronco. Houve variação qualitativa e quantitativa entre o lenho de caule e raiz. Camadas de crescimento distintas foram observadas no lenho de caule e raiz. Foram observados placas de perfuração simples nos elementos de vaso no lenho de caule e raiz. Fibras bifurcadas, com cavidades e interrupções da parede, e fibras septadas no lenho dos dois órgãos. Raios uni e multisseriados foram observados em caule e raiz, com uma a três células de largura em caules, com uma a quatro células de largura em raiz. As características quantitativas relevantes entre o lenho da raiz e caule em A. sellowiana foram comprimento, diâmetro e freqüência de vaso; diâmetro e espessura da parede da fibra; largura, altura e frequência de raio; diâmetro da pontoação intervascular.
\end{abstract}

Palavras-chave: Fibra, madeira, cerrado.

\section{COMPARED ANATOMY OF ROOT AND STEM WOOD OF Aegiphila sellowiana Cham. (VERBENACEAE)}

\begin{abstract}
This study compared the structural anatomy o stem and root wood of Aegiphila sellowiana Cham. (Verbenaceae). The study was conducted on a cerrado area in the town of Pratânia, São Paulo state. Three specimens of A. sellowiana were collected for the study. Stem samples were collected at a breast height $(1.30 \mathrm{~m}$ from the soil), root samples were collected 30 to $40 \mathrm{~cm}$ from the stem base. There were both qualitative and quantitative variation between root and stem wood. Distinct growth rings demarcated were observed in stem and root wood. Simple perforation plates were found in the vessel elements in root and stem wood. Forked fibers, fibers with cavities and interruptions in their wall, and septate fibers were observed in the wood of both organs. Uni-and multiseriate rays were found in the wood of the two organs, one to three cells wide in the stem and one to four cells wide in the root. The relevant quantitative characteristics between root and stem wood in A. sellowiana were: length, diameter and frequency of vessel; fiber wall diameter and thickness; ray width, height and frequency; and intervascular pit diameter.
\end{abstract}

Key words: Fiber, wood, cerrado.

\section{INTRODUÇÃO}

O gênero Aegiphila compreende cerca de 160 espécies arbóreas, arbustivas e algumas lianas com distribuição pantropical (GENTRY, 1993). Aegiphila sellowiana Cham. (Verbenaceae) é uma espécie arbórea típica do cerrado (SANO; ALMEIDA, 1998), entretanto, existem também registros de ocorrência dessa espécie em outros tipos de vegetações, como de florestas semidecíduas (LORENZI, 2002). A planta alcança de 4 a 7 metros de altura, mais conhecida como papagaio, tamanqueira ou pau-de-tamanco, com tronco e ramificações do caule, variando de 20 a $30 \mathrm{~cm}$ de diâmetro. As suas folhas são simples e opostas, floresce durante os meses de dezembro a janeiro e a maturação dos frutos ocorre de fevereiro a abril (LORENZI, 2002). Segundo o autor, a madeira de A. sellowiana apresentase leve, mole e baixa durabilidade natural, sendo muito utilizada para obras internas como caixotarias e confecções de tamancos.

Salvo as descrições anatômicas realizadas por Metcalfe e Chalk (1950) para o gênero, e por Détienne e Jacquet (1983) para a espécie Aegiphilla intermédia, não há informações a respeito da anatomia do lenho de caule e raiz de $A$. sellowiana.

Os estudos sobre anatomia do lenho têm sido realizados, preferencialmente, em caules, sendo poucos os estudos anatômicos que tratam sobre o lenho de raízes (GASSON; CUTLER, 1990). Segundo Cutler (1976), a dificuldade de coleta das raízes pode ser a causa dos poucos estudos anatômicos nesse órgão. Os trabalhos que comparam a anatomia do lenho de raiz com a de caule são ainda mais escassos (EWERS et al., 1997; GOULART; MARCATI, 2008; MACHADO et al., 1997; PSARAS; SOFRONIOU, 2004; RANJANI; KRISHNAMURTHY, 1987) e importantes, uma vez que essas análises comparadas,

${ }^{1}$ Bióloga, Pós-doutoranda em Ciência e Tecnologia da Madeira - Universidade Federal de Lavras/UFLA - Departamento de Ciências Florestais - Cx. P. 3037 - 37200-000 - Lavras, MG, Brasil - lopesgoulart@yahoo.com.br 
segundo Machado et al. (1997), permitem um melhor entendimento de adaptações ecológicas das espécies.

Neste trabalho, há contribuições com informações sobre a anatomia estrutural da madeira de raiz e caule de $A$. sellowiana Cham. (Verbenaceae), além de correlacionar as características anatômicas estruturais da raiz e do caule com as prováveis adaptações ecológicas da espécie no ambiente de cerrado.

\section{MATERIAL E MÉTODOS}

\section{1 Área de estudo}

O estudo foi conduzido em área de cerrado localizada em uma propriedade particular, Fazenda Palmeira da Serra, no município de Pratânia, estado de São Paulo ( $23^{\circ} 02^{\prime}$ ' 55, $5^{\prime \prime}$ S e 48 31' 26,1" W). Segundo Carvalho et al. (1991), o tipo climático do município é definido como Cwb (mesotérmico de inverno seco), dado obtido pela classificação de köeppen (1931) em que o mês mais quente não apresenta temperatura média maior que $22^{\circ} \mathrm{C}$, sendo o mês de julho o mais frio e seco. A precipitação média anual é de, aproximadamente, $1534 \mathrm{~mm}$ e a temperatura média de $20,3^{\circ} \mathrm{C}$. A estação seca estende-se de maio a setembro, sendo a média de precipitação de 38 a $89 \mathrm{~mm}$, respectivamente. O mês de janeiro predomina como o mais quente $\left(22,7^{\circ} \mathrm{C}\right)$ e úmido $(242 \mathrm{~mm})$ e o mês de julho o mais frio $\left(16,6^{\circ} \mathrm{C}\right)$ e seco $(38 \mathrm{~mm})$.

\subsection{Coleta e preparo do material}

Três espécimes de A. sellowiana foram coletados com, aproximadamente, a mesma altura, em fase adulta, e não muito distantes uns dos outros. Do material botânico coletado, foram preparadas exsicatas que foram depositadas no Herbário "Irina Delanova de
Gemtchujinicov" (BOTU) do Departamento de Botânica, Instituto de Biociências, UNESP, Campus de Botucatu, SP. Amostras do caule foram coletadas à altura do peito (AP), istoé, a 1,30 $\mathrm{m}$ do solo. As amostras de raiz foram coletadas de 30 a $40 \mathrm{~cm}$ da base do tronco. Os materiais lenhosos (caule e raiz) foram depositados na Xiloteca "Maria Aparecida Mourão Brasil" (BOTw), Tabela 1 do Departamento de Recursos Naturais-Ciências Florestais, da Faculdade de Ciências Agronômicas, UNESP, Campus de Botucatu, SP.

As amostras coletadas foram fixadas em FAA 70 (ácido acético, formaldeído e etanol 70\%) (BERLYN; MIKSCHE, 1976). Dessas amostras, foram retirados corpos de prova adequadamente orientados nos planos transversal, tangencial e radial, conforme recomendações da Comision Panamericana de Normas técnicas - COPANT (1974). Secções histológicas transversais e longitudinais tangenciais e radiais, com cerca de 15 a $20 \mu \mathrm{m}$ de espessura, foram obtidos em micrótomo de deslize (marca Reichert) com navalha tipo $\mathrm{C}$.

As secções obtidas foram separadas em dois grupos, um dos quais foi submetido ao processo de coloração com azul de astra aquoso a 1\% (ROESER, 1972) e safranina aquosa a 1\% (BUKATSCH, 1972). Enquanto o outro permaneceu sem coloração, as secções coradas e ao natural foram desidratadas e montadas em resina sintética, Entelan.

A dissociação dos elementos celulares foi realizada, segundo o método de Franklin (1945), modificado por Berlyn e Miksche (1976). O material dissociado foi corado com safranina a $1 \%$, em álcool $50 \%$. As lâminas semipermanentes, contendo o material dissociado foram montadas em solução aquosa de glicerina (1:1).

Tabela 1 - Informações gerais sobre os espécimes coletados de Aegiphila sellowiana Cham.

Table 1 - General information about the collected specimens of Aegiphila sellowiana Cham.

\begin{tabular}{|c|c|c|c|c|c|c|}
\hline Coletor & Órgão & $\begin{array}{c}\mathrm{N}^{\circ} . \\
\text { Xiloteca } \\
\left(\mathrm{BOT}_{\mathrm{w}}\right)\end{array}$ & $\begin{array}{c}\mathrm{N}^{\circ} . \\
\text { Herbário } \\
\text { BOTU }\end{array}$ & $\begin{array}{l}\text { Altura } \\
(\mathrm{m})\end{array}$ & $\begin{array}{l}\mathrm{DAP} * \\
(\mathrm{~cm})\end{array}$ & $\begin{array}{l}\text { Diâmetro das raízes } \\
\qquad(\mathrm{cm})\end{array}$ \\
\hline S.L. Goulart 7 & $\mathrm{C}$ & 1411 & 24.304 & 3,11 & 14 & - \\
\hline S.L. Goulart 7 & $\mathrm{R}$ & 1412 & - & - & - & 3,18 \\
\hline S.L. Goulart 9 & $\mathrm{C}$ & 1413 & 24.305 & 2,40 & 10 & - \\
\hline S.L. Goulart 9 & $\mathrm{R}$ & 1414 & - & - & - & 2,33 \\
\hline S.L. Goulart 11 & $\mathrm{C}$ & 1415 & 24.306 & 2,00 & 6,5 & - \\
\hline S.L. Goulart 11 & $\mathrm{R}$ & 1416 & - & - & - & 2,33 \\
\hline
\end{tabular}

(*) $\mathrm{DAP}=$ diâmetro à altura do peito $(1,30 \mathrm{~m}) . \mathrm{C}=$ caule. $\mathrm{R}=$ raiz.

(*) DAP = Breast Height diameter $(1.30 \mathrm{~m}) . C=$ stem. $R=$ root

Cerne, Lavras, v. 18, n. 4, p. 595-606, out./dez. 2012 


\subsection{Análises anatômicas qualitativas e quantitativas}

Para as análises anatômicas qualitativas, foram observadas, segundo as orientações propostas pelo IAWA Committee (1989) e pelas normas de procedimentos em estudos de anatomia da madeira de (CORADIN; MUÑIZ, 1992).

Análises anatômicas quantitativas foram realizadas, seguindo-se as recomendações do IAWA Committee (1989). Os dados quantitativos foram obtidos em microscópio de luz acoplado a câmera digital Axiocam e software para análise de imagens Axiovision, e transferidos para planilhas do programa Excel, para posterior análise estatística. Foram calculados também os índices de vulnerabilidade ( $v=$ diâmetros dos elementos de vaso/frequência de vasos) e de mesomorfia $(\mathrm{m}=\mathrm{v} \mathrm{x}$ comprimento dos elementos de vaso) (CARLQUIST, 1977). Para a realização das análises estatísticas, utilizou-se o programa SAS (Statistical Analysis System) e foram feitas análises de variância simples (p> $0,05)$ e teste de Tukey a $5 \%$ de probabilidade.

\section{RESULTADOS}

Características anatômicas qualitativas do lenho de caule e raiz - Camadas de crescimento distintas (Figuras 1a e 1b) demarcadas por anel semiporoso (Figuras la e 1b), faixa marginal de parênquima axial que é melhor demarcada em raízes (Figuras 1b e 1d), quando comparada com os caules (Figuras 1a e 1c), e espessamento radial das fibras no final do lenho tardio (Figuras 1c e 1d). Poros/Vasos: lenho com anel semiporoso, presente em caule (Figura 1a) e raiz (Figura 1b), vasos predominantemente solitários no caule (78\%) (Figura 1a), e na raiz (71\%) (Figura 1b), múltiplos de dois para o caule $(17 \%)$ e para a raiz $(21 \%)$, múltiplos de três para o caule $(4 \%)$ e para a raiz $(7 \%)$, múltiplos de quatro e cinco, (1\%) para o caule e raiz. Alguns vasos maiores estão agrupados tangencialmente de dois a quatro (Figura 1b). Placas de perfuração simples em elementos de vasos de caule e raiz (Figuras $2 \mathrm{a}-2 \mathrm{c}$ ). Algumas placas de perfuração apresentam a borda pontoada (Figura 2a). Apêndices podem ou não estar presentes (Figuras $2 \mathrm{~b}$ e $2 \mathrm{c}$ ), porém, quando presentes, ocorrem em uma ou em ambas as extremidades dos elementos de vaso (Figura 2c) tanto em caule quanto em raiz. Pontoações intervasculares areoladas alternas (Figura 2d), pontoações raio-vasculares alternas com abertura maior do que a das intervasculares (Figura 2e) para ambos os órgãos estudados. Tilos ocasionais presentes em vasos de caules (Figura 2f). Fibras: com pontoações diminutas (Figura 3a), no lenho de caule e raiz em ambas as paredes; septadas (Figura 3a) distribuídas esporadicamente por todo o lenho de caule e raiz. Paredes finas a espessas
(Figuras 1a-1d) para caule e raiz. Presença de fibras com cavidades (Figura 3b), em ambos os órgãos estudados, fibras bifurcadas (Figura 3c) tanto em caule quanto em raiz, e fibras com interrupção de parede (Figura 3d) em raiz e caule. Parênquima axial: em faixas, melhor evidenciado em raízes (Figuras 1b e 1d) e paratraqueal vasicêntrico a aliforme (Figuras 1a e 1b). A série parenquimática possui de três a oito células (Figura 3e), sendo a maioria de três a quatro em raiz e caule. Presença de parênquima bifurcado (Figura 3f) em raiz e caule. Raios: uni e multisseriados com uma a três células de largura em caule (Figura 3g), e uma a quatro células de largura em raiz (Figura 3h); com dois tipos de composição celular, sendo o caule com o corpo do raio com células procumbentes e a margem com células quadradas ou eretas (Figura 4b); com células eretas e quadradas misturadas, por meio do raio em raiz (Figura 4a). Presença ocasional de células envolventes de raio na raiz (Figura $3 \mathrm{~h}$ ). Cristais de formatos irregulares em células do parênquima axial em raiz (Figura 4c) e do radial em caule, (Figura 4d). Conteúdos orgânicos como grãos de amido no lenho de raiz e caule, nas células do parênquima axial e radial (Figura 4c).

As características quantitativas do lenho de caule e raiz estão apresentadas na Tabela 2 . Houve diferença estatística $(\mathrm{p}<0,05)$ para comprimento, diâmetro e freqüência de vaso, diâmetro e espessura da fibra, largura, altura e frequiência do raio, diâmetro da pontoação intervascular, como mostra a Tabela 3.

\section{DISCUSSÃO}

A estrutura anatômica qualitativa do lenho de $A$. sellowiana concorda em termos gerais, com a prévia descrição realizada para o gênero por Metcalfe e Chalk (1950) e com a descrição de Aegiphila intermedia realizada por Détienne e Jacquet (1983).

Camadas de crescimento distintas foram observadas no lenho de caule e raiz de $A$. sellowiana, porém, nas raízes, essas camadas estão melhor demarcadas do que no lenho dos caules. A presença de camadas de crescimento distintas, para essa espécie, pode estar relacionada a fatores ambientais. Worbes (1995), em seus estudos, verificou que para espécies de regiões tropicais, uma estação seca com duração de dois a três meses no ano, com precipitação menor que $60 \mathrm{~mm}$, é condição ambiental suficiente para a formação de camadas de crescimento no lenho. A região de estudo apresenta uma estação seca anual com duração de cinco meses e, nesse mesmo período, a precipitação está em torno de 38 a $89 \mathrm{~mm}$ o que pode estar provocando a formação da camada de crescimento no lenho da espécie.

Cerne, Lavras, v. 18, n. 4, p. 595-606, out./dez. 2012 


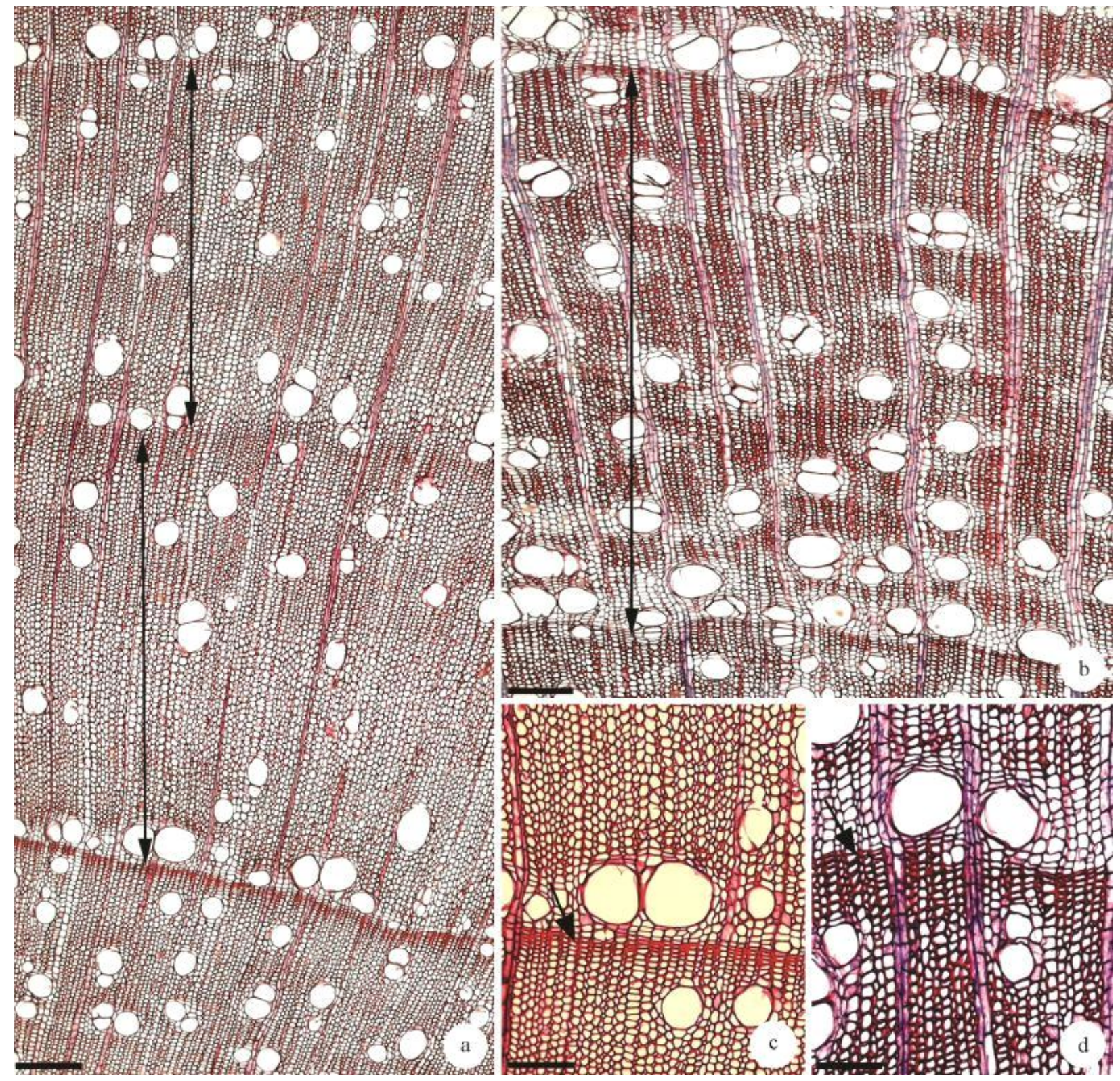

Figura 1 - Secções transversais do lenho de caule e raiz de Aegiphila sellowiana Cham. a - b. Camadas de crescimento distintas (setas). a. Caule. b. Raiz. c - d. Detalhe mostrando fibras espessadas e achatadas radialmente (setas) no final do lenho tardio. c. Caule. d. Raiz. Barra $=50 \mu \mathrm{m}(\mathrm{c}, \mathrm{d}) ; 100 \mu \mathrm{m}(\mathrm{a}, \mathrm{b})$.

Figure 1 - Crosswise sections of the wood of the stem and root of Aegiphila sellowiana Cham. $a-b$. Distinct growth layers (arrows). a. Stem. b. Root. $c-d$. Detail showing thickened and radially flattened fibers (arrows) at the end of the late wood. $c$. Stem. d. Root. Bar $=50 \mu m(c, d) ; 100 \mu m(a, b)$.

Cerne, Lavras, v. 18, n. 4, p. 595-606, out./dez. 2012 

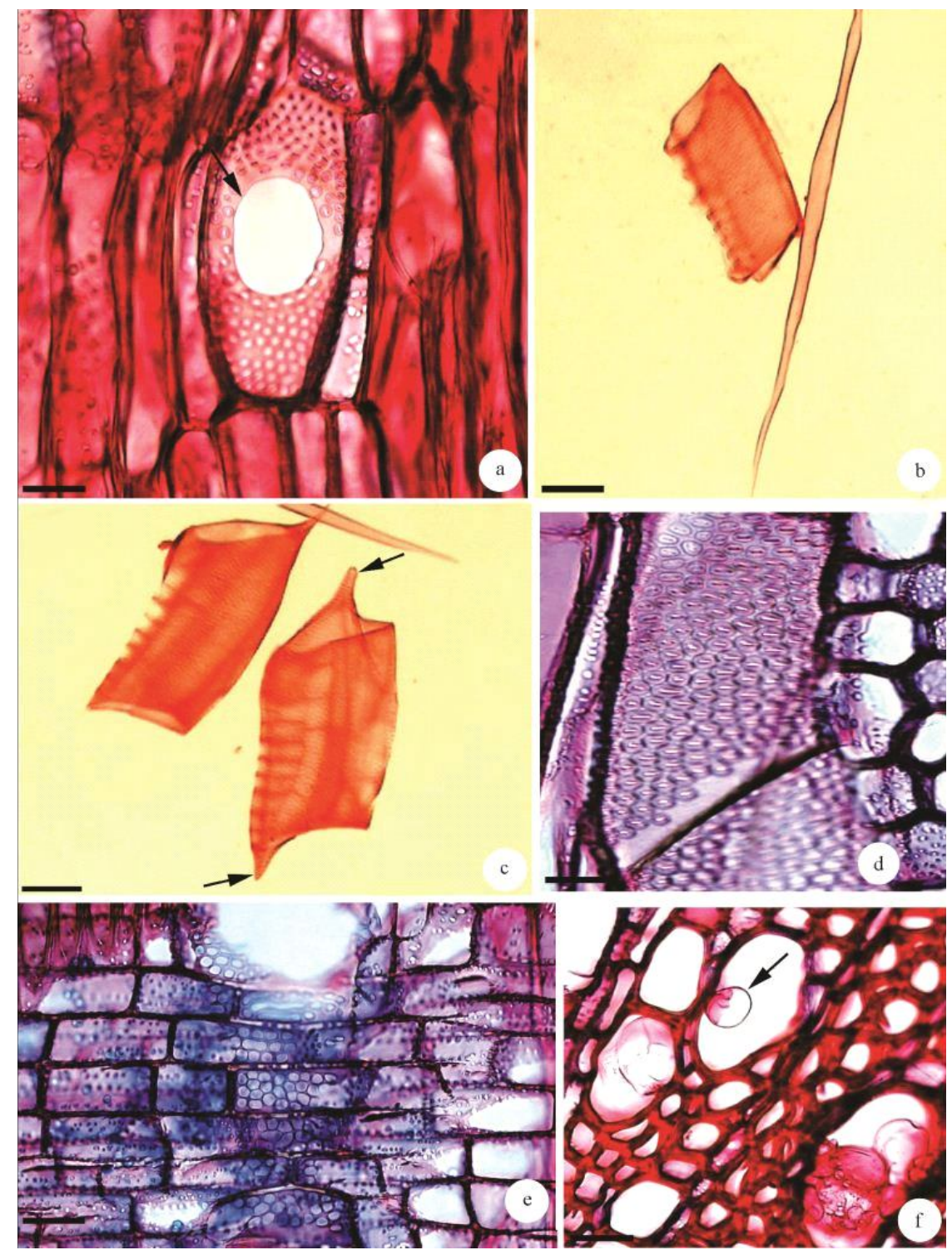

Figura 2 - Lenho de caule e raiz de Aegiphila sellowiana Cham. a. Secção longitudinal radial do lenho de raiz, mostrando placa de perfuração simples em vaso (seta). Notar a borda da placa de perfuração com pontoações areoladas, semelhantes às pontoações intervasculares. b - c. Elementos de vaso em macerado. b. Sem apêndice em lenho de caule. c. Com apêndices em uma ou em ambas as extremidades no lenho de raiz (setas). d. Secção longitudinal tangencial do lenho de caule, mostrando vasos com pontoações intervasculares areoladas alternas. e. Secção longitudinal radial em raiz mostrando pontoações raio-vasculares com abertura maior do que a das pontoações intervasculares. f. Tilo (seta) em vaso no lenho de caule. Barra $=30 \mu \mathrm{m}(\mathrm{a}, \mathrm{d}) ; 50 \mu \mathrm{m}(\mathrm{b}, \mathrm{c}, \mathrm{e}, \mathrm{f})$.

Figure 2 - Wood of stem and root of Aegiphila sellowiana Cham. a. Radial lengthwise section of the root wood, showing single perforation plates in vessel members (arrow). Notice the edge of the perforation plate with bordered vessel pits, similar to the intervascular pits. $b$ - $c$. Vessel elements in macerated material. $b$. Without appendage in stem wood. $c$. With appendage at one or at both the ends in the root wood (arrows). $d$. Tangential lengthwise section of the stem wood, showing vessels with alternate bordered intervascular pits. e. Radial lengthwise section in root showing ray-vascular pits with openings larger than those of the intervascular pits. f. Tilo (arrow) in vessel in the stem wood. Bar $=30 \mu \mathrm{m}(a, d) ; 50 \mu \mathrm{m}(b, c, e, f)$. 


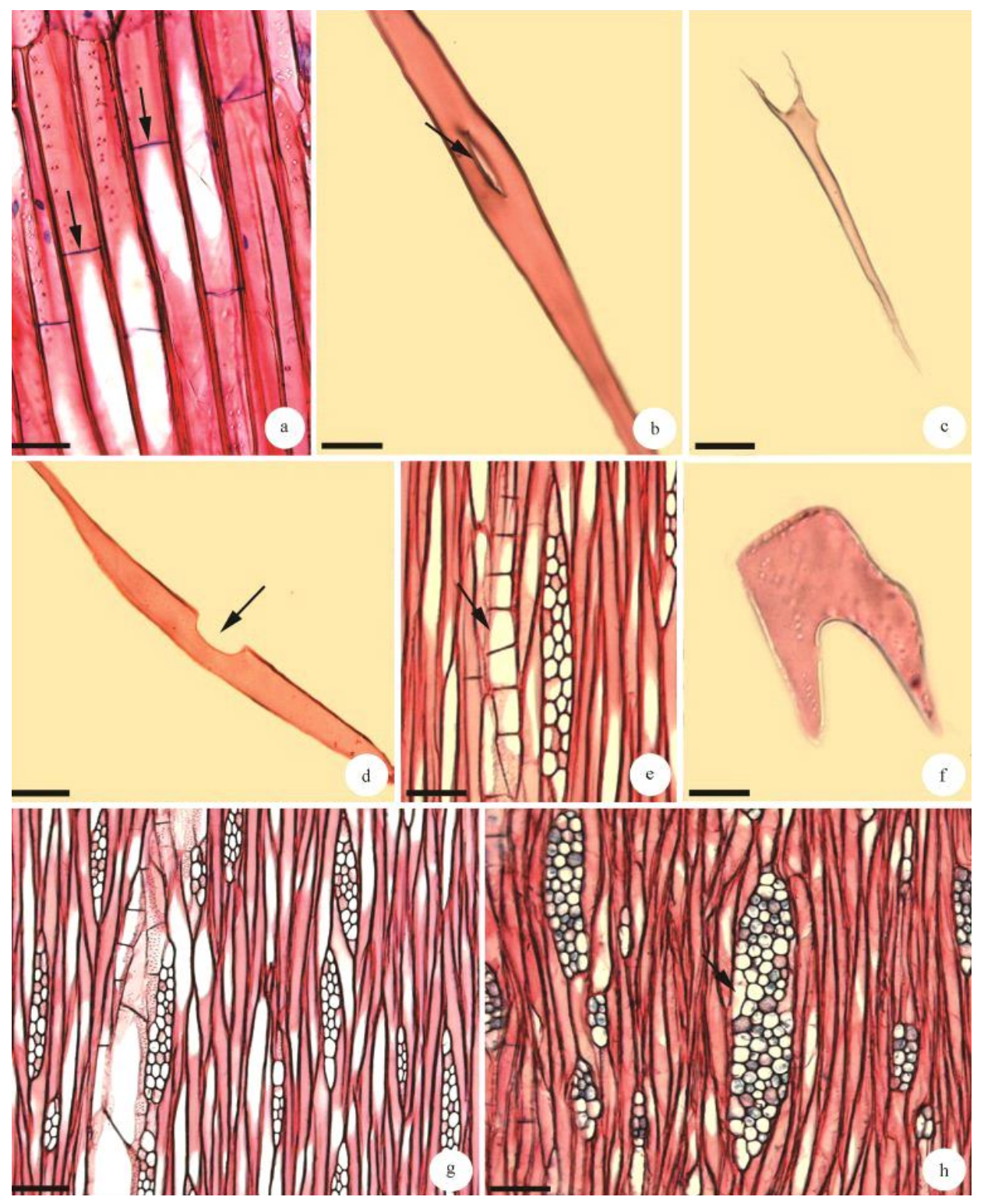

Figura 3 - Lenho de caule e raiz de Aegiphilla sellowiana Cham. a. Secção longitudinal tangencial de raiz, mostrando fibras septadas (setas) e com pontoações diminutas. b. Fibra com cavidade em macerado (seta), caule. c. Fibra bifurcada em macerado, raiz. d. Fibra com interrupção da parede em macerado (seta) raiz. e. Secção longitudinal tangencial do caule, mostrando série parenquimática com oito células (seta). f. Parênquima bifurcada em macerado de raiz. $\mathrm{g}$ - h. Secções longitudinais tangenciais de caule e raiz. g. Raios multisseriados de duas a três células de largura em caule. h. Raios uni e multisseriados com uma a quatro células de largura em raiz. Célula envolvente de raio (seta). Barra $=30 \mu \mathrm{m}$ (f); $50 \mu \mathrm{m}(\mathrm{a}-\mathrm{b}$ d); $80 \mu \mathrm{m}(\mathrm{e}) ; 100 \mu \mathrm{m}(\mathrm{c}, \mathrm{g}-\mathrm{h})$.

Figure 3 - Stem and root wood of Aegiphilla sellowiana Cham. a. Tangential lengthwise section of root showing septate fibers (arrows) and with tiny pits. $b$. Fiber with cavities in macerated material (arrow), stem. $c$. Forked fiber in macerated material root. d. Fiber with an interruption of the wall in macerated material (arrow) root.e. Tangential lengthwise section of the stem showing an eight-celled parenchyma series (arrow).f. Forked parenchyma in root macerated material $g-h$. Tangential lengthwise cuts of stem and root. g. Multiseriate rays two to three cells in breadth in stem. h. Uni-and-multiseriate rays with one to four cells in breadth in root. Ray sheath cells (arrow). Bar $=30$ $\mu m(f)$; $50 \mu m(a-b d)$; $80 \mu m(e) ; 100 \mu m(c, g-h)$.

Cerne, Lavras, v. 18, n. 4, p. 595-606, out./dez. 2012 


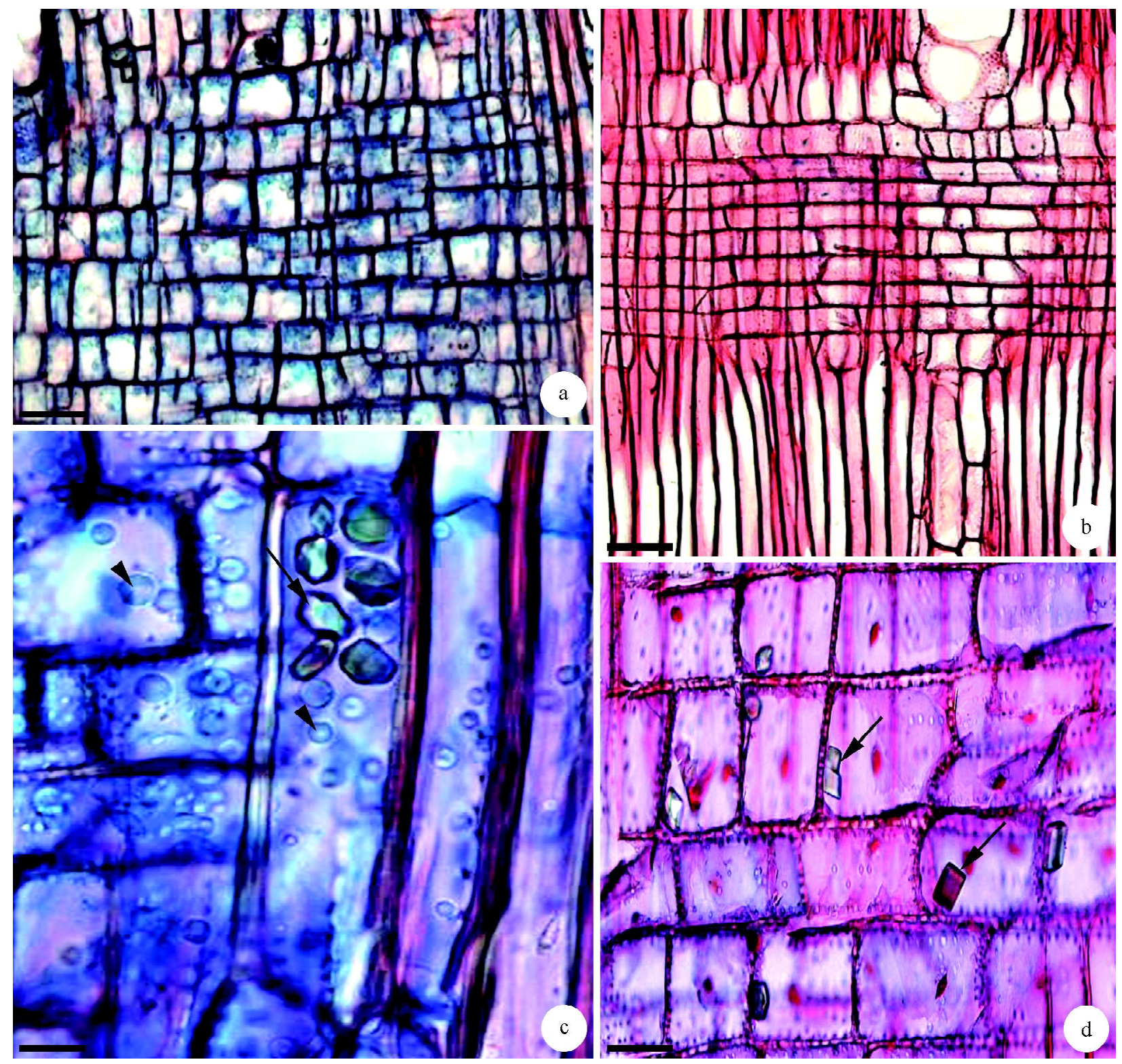

Figura 4 - Secções longitudinais radiais do lenho de caule e raiz de Aegiphila sellowiana Cham. a. Células quadradas e eretas misturadas no raio em raiz. b. Corpo do raio com células procumbentes e uma a duas camadas de células quadradas e eretas na margem em caule. c. Cristais prismáticos e de formatos irregulares (seta) em célula do parênquima axial. Notar os grãos de amido (cabeça de seta) nas células do parênquima axial e radial em raiz. d. Cristais prismáticos e de formatos irregulares (setas) nas células do parênquima radial em caule. Barra $=30 \mu \mathrm{m}$ c-d; $100 \mu \mathrm{m}$ a-b.

Figure 4-Radial lengthwise cuts of the root and stem wood of Aegiphila sellowiana Cham. a. Upright and square cells mixed in the ray in root. b. Ray body with procumbent cells and one to two layers of square and upright cells on the edge in stem. $c$. Prismatic and irregular-shaped crystals (arrows) in axial parenchyma cell. Notice starch grains (arrow head) axial and radial parenchyma in root. $d$. Prismatic and irregular-shaped crystals (arrows) in the radial parenchyma in stem. Bar $=30 \mu \mathrm{m} c$-d; 100 $\mu m a-b$. 


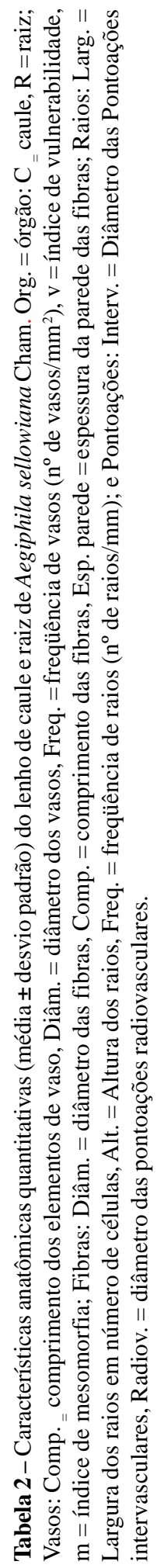

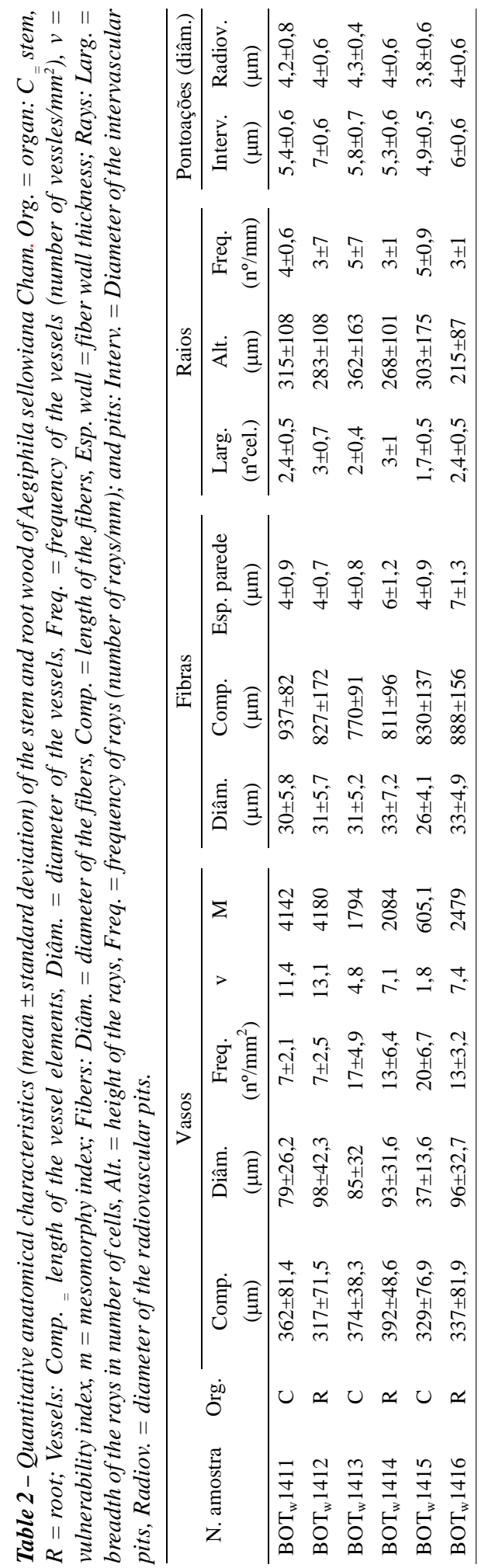

As raízes de $A$. sellowiana apresentam camadas de crescimento melhor demarcadas do que as dos caules, o que não está de acordo com o que foi relatado por Zimmermann e Brown (1971), que mencionam uma menor evidência das camadas de crescimento em lenho de raiz, quando comparado com lenho de caule. Estudos em espécies brasileiras, como os de Dias-Leme (1994) com espécies da família Euphorbiaceae, Machado et al. (1997) com Styrax camporum (Styracaceae) e Esemann-Quadros (2001) com Clusia criuva (Clusiaceae), demonstram camadas de crescimento distintas no lenho de raízes, o que concorda com o que foi observado em A. sellowiana e se opõe ao que foi relatado por Zimmermann e Brown (1971).

Anéis semiporosos foram encontrados no lenho de caule e raiz em A. sellowiana. Segundo Metcalfe e Chalk (1950), essa característica é comum em espécies da família Verbenaceae. Anéis semiporosos proporcionam à espécie, vantagem sobre as de porosidade difusa, pois, segundo Wheeler e Baas (1991) fornecem segurança e eficiência na condução de água. Segundo os autores, os vasos de maior diâmetro são mais eficientes no transporte de água em épocas de maior disponibilidade hídrica no solo e os vasos de menor diâmetro são mais seguros em época de seca. A presença de anéis semiporosos no lenho de caule e raiz em A. sellowiana pode assim estar relacionado à sazonalidade hídrica do ambiente em que as plantas cresceram, ou seja, o cerrado.

Placas de perfuração simples foram observadas tanto no lenho de caule quanto no lenho de raiz em $A$. sellowiana. Apesar de alguns estudos indicarem que a presença de placas de perfuração simples nos vasos pode estar relacionada à maior eficiência na condução de água dentro da planta (WHEELER; BAAS, 1991), estudos recentes não sustentam essa teoria, porque o ganho em condutividade hidráulica em vasos com placas de perfuração simples, quando comparados com os de placas de perfuração múltiplas é muito pequeno (ELLERBY; ENNOS, 1998).

Quantitativamente, houve grande variação entre os caules e entre as raízes dos espécimes. De uma forma geral, o comprimento dos elementos de vaso foi maior no lenho de caule do que no de raiz. Esse resultado concorda com o de Machado et al. (1997) em Styrax camporum (Styracaceae), espécie que também ocorre em cerrado, entretanto se opõe ao que foi indicado nos estudos de Cutler (1976) com espécies de clima temperado e Psaras e Sofroniou (1999), com espécie do mediterrâneo.

Cerne, Lavras, v. 18, n. 4, p. 595-606, out./dez. 2012 
Tabela 3 - Análise quantitativa do lenho de caule e raiz de todos os espécimes de Aegiphila sellowiana Cham. Diâm. = diâmetro; freq. $=$ frequência; Esp. $=$ espessura; Pont. $=$ Pontoações.

Table 3 - Quantitative analysis of the wood of the stem and root of all the specimens of Aegiphila sellowiana Cham. Diâm. = diameter; Freq. Frequency; Esp. = thickness; Pont. = Pits.

\begin{tabular}{|c|c|c|c|c|c|c|}
\hline Características & & & $\begin{array}{l}\text { Média } \\
(\mu \mathrm{m})\end{array}$ & $\begin{array}{c}\text { Tukey } \\
5 \%\end{array}$ & $\begin{array}{c}\text { Estatística de } \\
\text { F }\end{array}$ & $\begin{array}{c}\text { Valor de } \\
\text { P }\end{array}$ \\
\hline \multirow{10}{*}{ Vasos } & \multirow{2}{*}{ Comprimento $(\mu \mathrm{m})$} & Caule & 355 & A & \multirow{2}{*}{13} & \multirow{2}{*}{0,0004} \\
\hline & & Raiz & 315 & B & & \\
\hline & \multirow{2}{*}{ Diâm. grande $(\mu \mathrm{m})$} & Caule & 91 & A & \multirow{2}{*}{3} & \multirow{2}{*}{0,0631} \\
\hline & & Raiz & 100 & A & & \\
\hline & \multirow{2}{*}{ Diâm. médio ( $\mu \mathrm{m})$} & Caule & 56 & A & \multirow{2}{*}{4} & \multirow{2}{*}{0,0382} \\
\hline & & Raiz & 61 & B & & \\
\hline & \multirow{2}{*}{ Diâm. pequeno $(\mu \mathrm{m})$} & Caule & 35 & A & \multirow{2}{*}{6} & \multirow{2}{*}{0,0127} \\
\hline & & Raiz & 39 & B & & \\
\hline & \multirow{2}{*}{ Freq. $\left(\mathrm{n}^{\mathrm{o}} / \mathrm{mm}^{2}\right)$} & Caule & 15 & A & \multirow{2}{*}{15} & \multirow{2}{*}{0,0001} \\
\hline & & Raiz & 11 & $\mathrm{~B}$ & & \\
\hline \multirow{6}{*}{ Fibras } & \multirow{2}{*}{ Comprimento $(\mu \mathrm{m})$} & Caule & 846 & A & \multirow{2}{*}{0,03} & \multirow{2}{*}{0,8551} \\
\hline & & Raiz & 842 & A & & \\
\hline & \multirow{2}{*}{ Diâm. $(\mu \mathrm{m})$} & Caule & 29 & A & \multirow{2}{*}{12} & \multirow{2}{*}{0,0006} \\
\hline & & Raiz & 32 & $\mathrm{~B}$ & & \\
\hline & \multirow{2}{*}{ Esp. da parede $(\mu \mathrm{m})$} & Caule & 4 & A & \multirow{2}{*}{49} & \multirow{2}{*}{0,0001} \\
\hline & & Raiz & 6 & $\mathrm{~B}$ & & \\
\hline \multirow{6}{*}{ Raios } & \multirow{2}{*}{ Largura (nº́lula) } & Caule & 2 & A & \multirow{2}{*}{70} & \multirow{2}{*}{0,0001} \\
\hline & & Raiz & 3 & B & & \\
\hline & \multirow{2}{*}{ Altura $(\mu \mathrm{m})$} & Caule & 327 & A & \multirow{2}{*}{14} & ב \\
\hline & & Raiz & 256 & $\mathrm{~B}$ & & 0,0003 \\
\hline & Fron $\left(\mathrm{n}^{\circ} / \mathrm{mm}\right)$ & Caule & 5 & A & 130 & 00001 \\
\hline & Fтеч. (II /IIIII) & Raiz & 3 & $\mathrm{~B}$ & 130 & 0,0001 \\
\hline Pont. & Dînm & Caule & 5 & A & 70 & 00001 \\
\hline intervascular & Didill. ( $\mu \mathrm{mi})$ & Raiz & 6 & B & 20 & 0,0001 \\
\hline Pont. raio- & Dînm (um) & Caule & 4 & A & 1 & 02170 \\
\hline vascular & Didill. ( $\mu$ iा) & Raiz & 4 & A & 1 & $0,34 / 0$ \\
\hline
\end{tabular}

O diâmetro dos vasos, quando analisados juntos, vasos de grande, médio e pequeno diâmetro, foi maior no lenho de raízes do que nos caules em dois espécimes. Quando analisados separadamente, vasos de grande diâmetro, médio e pequeno, seguiu tendência de maiores valores para a raiz. Os resultados encontrados seguem as tendências apontadas na literatura (MACHADO et al.,
1997; PSARAS; SOFRONIOU, 2004). Entretanto, segundo Cutler (1976), não devem ser feitas generalizações para tendência de vasos de maior diâmetro na raiz.

Com relação à frequência de vasos, foi verificado, em dois espécimes, maior valor no lenho de caule, quando comparado com o lenho da raiz. Esse resultado discorda dos estudos de Cutler (1976), Esemann-Quadros (2001) eMorrison 
(1953), porém está de acordo com os estudos realizados por Machado et al. (1997) e Psaras e Sofroniou (2004). Como já comentado anteriormente, a variação encontrada entre os espécimes dificulta a discussão. Cutler (1976) comenta que deve tomar cuidado ao fazer generalizações em ralação à frequência de vasos entre caule e raiz, pois, em seus próprios trabalhos o autor encontrou variação nos seus resultados.

Apesar de muito variáveis, os valores dos índices de vulnerabilidade $(1,8$ a 13,1) e de mesomorfia (605,1 a 4180) indicam que $A$. sellowiana está adaptada a condições mésicas. Esses dados surpreendem, já que as plantas dessa espécie estão em um ambiente com sazonalidade hídrica e solo pobre (cerrado). Entretanto, foi verificado, neste estudo (observação de campo), que as raízes dessas plantas são axiais e profundas, assim, é possível que essas raízes sejam profundas o suficiente para encontrar água alguns metros abaixo no solo, no lençol freático, e dessa forma as plantas não sofreriam tanto a falta de água nos períodos de seca. Ressaltamos que não foi realizado um estudo experimental para a comprovação desse fato.

A presença de fibras septadas no lenho de caule e raiz de $A$. sellowiana pode estar relacionada à função de armazenamento de água e de substâncias de reserva nessas plantas, como mencionado por Chalk (1989), já que essas plantas se encontram em cerrado onde o solo dessa área, segundo Goulart e Marcati (2008) apresenta alterações químicas e físicas e há variação sazonal das distribuições das chuvas.

Fibras bifurcadas foram observadas no lenho de caule e raiz em A. sellowiana. Esemann-Quadros (2001) observou fibras com terminações variadas em Clusia criuva Camb. (Clusiaceae) e concorda com e Esau (1967), que essas variações são oriundas de crescimento intrusivo e também pode formar cavidades intrusivas nessas células. Fibras com cavidades e com interrupções da parede foram observadas no lenho de caule e raiz da espécie. As cavidades já foram observadas em traqueídes, fibras e parênquima axial nas diferentes famílias de dicotiledôneas (DIAS-LEME; ANGYALOSSY-ALFONSO, 1998).

Raios mais largos foram observados nas raízes, quando comparados com os dos caules. Alves e Angyalossy-Alfonso (2002) mencionam que raios mais largos nas raízes podem representar uma maior eficiência no transporte radial e Lebedenko (1962) menciona que os raios mais largos nas raízes podem estar relacionados a uma maior capacidade de reserva dessas raízes. Em $A$. sellowiana, a maior largura dos raios nas raízes pode estar relacionada tanto a maior eficiência no transporte radial quanto à reserva de nutrientes.

Cerne, Lavras, v. 18, n. 4, p. 595-606, out./dez. 2012

\section{CONCLUSÕES}

A presença de camadas de crescimento no lenho de caule e raiz em $A$. sellowiana pode estar relacionada às variações pluviométricas durante o ano; fibras septadas em caule e raiz e raios mais largos no lenho de raiz podem estar relacionados ao armazenamento de água e substâncias de reserva, o que garantiria o suprimento de nutrientes necessários nos períodos desfavoráveis; os valores do índice de vulnerabilidade e de mesomorfia indicam que a espécie está adaptada a condições mésicas; as características quantitativas mais informativas que diferenciam o lenho da raiz do de caule em A. sellowiana foram comprimento, diâmetro e frequência de vasos, diâmetro e espessura da parede das fibras, largura, altura e frequência dos raios e diâmetro das pontoações intervasculares.

\section{AGRADECIMENTOS}

À Universidade Estadual Paulista Júlio de Mesquita Filho (UNESP) pela oportunidade de realização do trabalho.

\section{REFERÊNCIAS}

ALVES, E. S.; ANGYALOSSY-ALFONSO, V. Ecological trends in wood anatomy of some Brazilian species: II., axial parenchyma, rays and fibres. IAWA Journal, Utrecht, v. 23, n. 4, p. 391-418, 2002.

BERLYN, G. P.; MIKSCHE, J. P. Botanical microtechnique and cytochemistry. Ames: Yowa State University, 1976.

BUKATSCH, F. Bemerkungen zur Dappelfarbung Astrablausafranin. Mikrokosmos, Stuttgart, v. 61, p. 255, 1972.

CARLQUIST, S. Ecological factors in wood evolution: a floristic approach. American Journal of Botany, Columbus, v. 64, p. 887-896, 1977.

CARVALHO, W. A.; PANOSO, L. A.; MORAES, M. H. Levantamento semidetalhado dos solos da fazenda experimental Edgardia, Botucatu, SP. Botucatu: UNESP, 1991.

CHALK, L. Fibres. In: METCALFE, C. R.; CHALK, L. (Ed.). Anatomy of the dicotyledons: wood structure and conclusion of the general introduction. $2^{\text {nd }}$ ed. Oxford: Oxford University, 1989. v. 2. 
COMISION PANAMERICANA DE NORMAS

TÉCNICAS. Descriptión de características generales, macroscopicas y microscópicas de la madera Angiospermae Dicotiledóneas. Caracas, 1974. 19 p.

CORADIN, V. T. R.; MUNIZ, G. B. Normas de procedimentos em estudos de anatomia de madeira: $\mathrm{I}$. Angiospermae. II. Gimnospermae. Brasília: IBAMA, 1992.

CUTLER, D. F. Variation in root wood anatomy. Leiden Botanical Series, Wageningen, v. 3, p. 143-156, 1976.

DÉTIENNE, P.; JACQUET, P. Atlas d'identification des bois de $\mathrm{l}^{\mathbf{k}}$ anatomie et regions voisines. Nogent-sur-Marne : Centre Technique Forestier Tropical, 1983.

DIAS-LEME, C. L. Anatomia comparada do lenho do caule, raiz e ramo de algumas espécies de Euphorbiaceae da Mata Atlântica. 1994. Dissertação (Mestrado em Botânica) - Universidade de São Paulo, São Paulo, 1994.

DIAS-LEME, C. L.; ANGYALOSSY-ALFONSO, V. Intrusive cavities in Euphorbiaceae fiber walls. IAWA Journal, Utrecht, v. 19, n. 3, p. 79-83, 1998.

ELLERBY, D. J.; ENNOS, A. R. Resistances to fluid flow of model xylem vessels with simple and scalariform perforation plates. Journal of Experimental Botany, Oxford, v. 49, n. 323, p. 979-985, 1998.

ESAU, K. Plant anatomy. $2^{\text {nd }}$ ed. New York: J. Wiley, 1967.

ESEMANN-QUADROS, K. Anatomia do lenho de Clusia criuva Camb. (Clusiaceae): órgãos, hábitos e ambientes. 2001. 132 p. Tese (Doutorado em Botânica) - Universidade de São Paulo, São Paulo, 2001.

EWERS, F. W.; CARLTON, M. R.; FISHER, J. B.; KOLB, K. J.; TYREE, M. P. Vessel diameters in roots versus stems of tropical lianas and other growth forms. IAWA Journal, Utrecht, v. 18, n. 3, p. 261-279, 1997.

GASSON. P.E.; CUTLER. F. Root anatomy of 17 genera growing the Britsh Isles. IAWA Bulletin, Leiden, v.11, n. 1, p. 3-36. 1990.

GENTRY, A. H. A field gude to the families and genera of wood plants of northwest South America. Chicago: University of Chicago, 1993.
GOULART, S. L.; MARCATI, C. R. Anatomia comparada do lenho em raiz e caule de Lippia salviifolia Cham. (Verbenaceae). Revista Brasileira de Botânica, São Paulo, v. 31, n. 2, p. 263-275, 2008.

IAWA COMMITTEE. List of microscopic features for hardwood identification. IAWA Bulletin, Leiden, v. 10, n. 3, p. 219-332, 1989.

KÖEPPEN, W. Climatologia. Buenos Aires: Fundo de Cultura Econômica, 1931. 338 p.

LEBEDENKO, L. A. Comparative anatomical analysis of the mature wood of roots and stems of some wood plants. Trudy Institute Lesa i Drevesiny Akademie Nauk, Leningrad, v. 51, p. 124-134, 1962.

LORENZI, H. Árvores brasileiras: manual de identificação e cultivo de plantas arbóreas nativas do Brasil. Nova Odessa: Instituto Plantarum, 2002. 384 p.

MACHADO, S. R.; ANGYALOSSY-ALFONSO, V.; MORRETES, B. L. Comparative wood anatomy of root and stem in Styrax camporum (Styracaceae). IAWA Journal, Utrecht, v. 18, n. 1, p. 13-25, 1997.

METCALFE, C. R.; CHALK, L. Anatomy of the dicotyledons. Oxford: Clarendon, 1950.

MORRISON, T. M. Comparative histology of secondary xylem in buried end exposed roots of dicotyleonous trees. Phytomorphology, New Delhi, v. 3, n. 4, p. 427-430, 1953.

PSARAS, G. K.; SOFRONIOU, I. Stem and root wood anatomy of the shrub Phlomis fruticosa (Labiatae). IAWA Journal, Utrecht, v. 25, n. 1, p. 71-77, 2004.

PSARAS, G. K.; SOFRONIOU, I. Wood anatomy of Capparis spinosa from an ecological perspective. IAWA Journal, Utrecht, v. 20, n. 4, p. 419-429, 1999.

RANJANI, K.; KRISHNAMURTHY, K. V. A comparative study of root and stem woods of some members of the Mimosoideae (Leguminosae). Journal of the Arnold Arboretum, Cambridge, v. 68, p. 349-355, 1987.

ROESER, K. R. Die nadel der schuwarz kiefermasssenprodukt und kunstwerk der nature. Mikrokosmos, Stuttgart, v. 61, p. 33-36, 1972.

Cerne, Lavras, v. 18, n. 4, p. 595-606, out./dez. 2012 
SANO, S. M.; ALMEIDA, S. P. Cerrado ambiente e flora. Planaltina: EMBRAPA, 1998.

WHEELER, E. A.; BAAS, P. A survey of the fossil record for dicotyledonous wood and its significance for evolutionary and ecological wood anatomy. IAWA Bulletin, Leiden, v. 12, p. 275-332, 1991.
WORBES, M. How to measure growth dynamics in tropical trees: a review. IAWA Journal, Utrecht, v. 16, p. 337-351, 1995.

ZIMMERMANN, M. H.; BROWN, C. L. Trees: structure and function. Berlin: Springer, 1971. 